\title{
Author Correction: SARS-CoV-2 infection and COVID-19 vaccination rates in pregnant women in Scotland
}

Sarah J. Stock (D), Jade Carruthers, Clara Calvert, Cheryl Denny iD, Jack Donaghy, Anna Goulding (iD, Lisa E. M. Hopcroft,

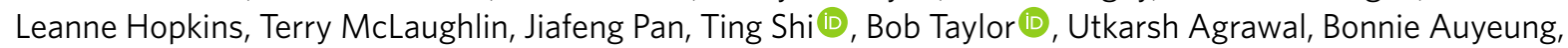
Srinivasa Vittal Katikireddi (D), Colin McCowan, Josie Murray, Colin R. Simpson (D), Chris Robertson, Eleftheria Vasileiou, Aziz Sheikh iD and Rachael Wood

Correction to: Nature Medicine https://doi.org/10.1038/s41591-021-01666-2, published online 13 January 2022.

In the version of this article initially published, a Statistical Analysis subsection was not present in the Methods and has now been included. Further, the Data availability statement has been amended to clarify that patient-level data may be available to approved researchers after securing relevant permissions from Public Health Scotland via the Public Benefit and Privacy Panel.

The changes have been made to the online version of the article.

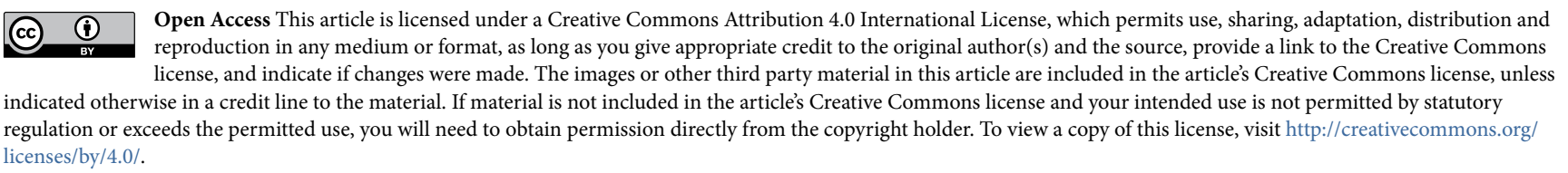

Published online: 4 February 2022

https://doi.org/10.1038/s41591-022-01730-5

(๑) The Author(s) 2022

\section{Author Correction: A combined risk score enhances prediction of type 1 diabetes among susceptible children}

Lauric A. Ferrat (D), Kendra Vehik (D), Seth A. Sharp, Åke Lernmark (D), Marian J. Rewers, Jin-Xiong She, Anette-G. Ziegler, Jorma Toppari (D), Beena Akolkar, Jeffrey P. Krischer, Michael N. Weedon, Richard A. Oram, William A. Hagopian (D, TEDDY Study Group and Committees

Correction to: Nature Medicine https://doi.org/10.1038/s41591-020-0930-4, published online 7 August 2020.

In the originally published version of this Letter, there was an error in the spelling of an author name in the TEDDY Study Group. Specifically, Xiangjun Tian's name initially appeared as "Xianjun Tian." Further, in the PDF version of the original article, the name of Henry Erlich (Center for Genetics Children's Hospital Oakland Research Institute, Oakland, CA, USA) was omitted from the Genetics contributors section of the TEDDY Study Group. The changes have been made to the html and PDF versions of the Letter.

Published online: 14 February 2022

https://doi.org/10.1038/s41591-021-01631-z

(c) The Author(s), under exclusive licence to Springer Nature America, Inc. 2022 